\title{
Keeping the fundamentals in mind
}

\author{
Christian Pizarro, MD
}

See related article on pages 1095-100.

Despite important improvements in surgical outcomes, management of patients with single-ventricle physiology and systemic outflow obstruction remains difficult, and renewed efforts are aimed at achieving improved functional outcomes. The work presented by DeCampli and colleagues ${ }^{1}$ in this issue of the Journal represents a new approach to simplify the intervention commonly undertaken as the second-stage palliation in those patients who have previously undergone a hybrid procedure for single-ventricle physiology. As stated by DeCampli and colleagues, 1 "a substantial decrease in trauma at the second stage could tip the balance in favor of the hybrid approach." There is no doubt that avoidance of a steep learning curve, extensive arch dissection, and need for a Damus-Kaye-Stansel anastomosis are appealing features. Many questions remain, and the advisability of this approach remains to be proved.

The first concern relates to the possibility of compromising the potential for growth. Although native tissues are preserved in some crucial areas, these are covered by circumferential metal stents, which, as we have learned while performing reoperations, commonly trigger a tremendous inflammatory response leading to perivascular fibrosis, dense adhesions, and extraordinary scarring. Little doubt exists that this will create the need for repeated interventions (and the vascular access necessary for them) to achieve the ultimate desired dimension. Moreover, the deployment of metal stents would create a formidable surgical challenge if future interventions were required. In addition to the direct mechanical effect of hardware deployment, physiologic effects should be considered. These include the potential impact on the common development of aneurysmal dilation of the neoaortic root and its potential effects on semilunar valve competence, ${ }^{2}$ as well as the deleterious effect on the elastic properties associated with increased stiffness of the neoaorta, loss of impulse propagation, ${ }^{3}$ and its potential effects on a Fontan physiology. In light of these important considerations, it seems counterintuitive to pursue a management strategy

\footnotetext{
From the Alfred I duPont Hospital for Children, Wilmington, Del.

Disclosures: Author has nothing to disclose with regard to commercial support.

Received for publication Feb 7, 2015; accepted for publication Feb 7, 2015.

Address for reprints: Christian Pizarro, MD, Alfred I duPont Hospital for Children,

Nemours Cardiac Center, 1600 Rockland Rd, Wilmington, DE 19899 (E-mail:

Christian.Pizarro@nemours.org).

J Thorac Cardiovasc Surg 2015;149:1101

$0022-5223 / \$ 36.00$

Copyright (c) 2015 by The American Association for Thoracic Surgery

http://dx.doi.org/10.1016/j.jtcvs.2015.02.022
}

that leads to perpetuating the discontinuity of the aortic arch and the unknown late effects of 2 systemic circulations connected in parallel.

Although it is difficult to resist the appeal of a procedure that is "significantly less surgically complicated," it must be clear that the ultimate goal for these patients is to achieve the desired circulation while preserving cardiopulmonary function and minimizing the potential for morbidity and the total number of interventions. The approach suggested here, although it uses new and improved imaging, hardware, and delivery systems, seems reminiscent of the initial palliative strategies used to manage aortic arch interruption. As we know 3 decades later, these created a setup for multiple and recurrent interventions, associated with scarring, fibrosis, and unintended effects, which complicated further surgery and intervention. ${ }^{4}$ Finally, as DeCampli and colleagues ${ }^{1}$ have clearly pointed out, the presence of sufficient antegrade blood flow to perfuse the brachiocephalic vessels is essential, limiting the applicability of this approach among patients with single-ventricle physiology and systemic outflow obstruction.

There is no doubt that in the current era a collaborative approach between surgeons and cardiologists should be pursued and facilitated, as this could provide unique opportunities to innovate and explore novel solutions. We must, however, never compromise the potential to achieve the desired circulation even when confronted with the appeal of a simpler and less traumatic intervention. In addition, as we pursue these efforts to innovate and discover, it is imperative that new approaches be held to the same standard in terms of effectiveness, durability, and reproducibility.

Ultimately, a robust and objective process should allow us to answer whether it is reasonable to create a circulation in which interruption of the aortic arch is perpetuated and associated with need for multiple reinterventions, with the sole purpose of avoiding a surgical reconstruction which nowadays is associated with a mortality of less than $10 \%$ for those patients with anatomic substrates described here. That could be hard to demonstrate.

\section{References}

1. DeCampli WM, Fleishman CE, Nykanen DG. Hybrid approach to the comprehensive stage II operation in a subset of single-ventricle variants. J Thorac Cardiovasc Surg. 2015;149:1095-100.

2. Cohen MS, Marino BS, McElhinney DB, Robbers-Visser D, van der Woerd W, Gaynor JW, et al. Neo-aortic root dilatation and valve regurgitation up to 21 years following staged reconstruction for hypoplastic left heart syndrome. J Am Coll Cardiol. 2003;42:533-40.

3. Sezer SS, Narin N, Ozyurt A, Onan SH, Pamukcu O, Argun M, et al. Cardiovascular changes in children with coarctation of the aorta treated by endovascular stenting. J Hum Hypertens. 2014;28:372-7.

4. Jonas RA, Quaegebeur JM, Kirklin JW, Blackstone EH, Daicoff G. Outcomes in patients with interrupted arch and ventricular septal defect. A multiinstitutional study. J Thorac Cardiovasc Surg. 1994;107:1099-109; discussion 1109-13. 